\title{
Analisis Pengaruh Kualitas Website Maxserver Menggunakan Webqual 4.0 Terhadap Kepuasan Pengguna Pada PT.MCS
}

\author{
Ahmad Ishaq ${ }^{1}$, Toni Sukendar², Mohammad Ikhsan Saputro ${ }^{3}$, Achmad Sumbaryadi \\ Universitas Bina Sarana Informatika, Universitas Bina Sarana Informatika , Universitas Mohammad Husni \\ Thamrin, Universitas Bina Sarana Informatika \\ ishaq@bsi.ac.id,Toni.tns@bsi.ac.id,m.ikhsan68@gmail.com,achmad.acs@bsi.ac.id
}

\begin{abstract}
ABSTRAK
Layanan suatu website perlu diukur untuk mengetahui tingkat kepuasan pengguna dan memperoleh umpan balik. Dalam penelitian ini kualitas website Maxserver diukur dengan menggunakan metode webqual 4.0. Webqual merupakan instrumen yang menilai kualitas suatu website menurut persepsi pengguna akhir. Analisis regresi linier berganda digunakan untuk menguji hubungan antar dimensi dari webqual 4.0 dengan kepuasan pengguna. Responden dalam penelitian ini adalah pengguna yang sudah berlangganan menggunakan produk dari maxserver. Jumlah sampel dalam penelitian ini sebanyak 122 responden. Data penelitian diperoleh dari hasil penyebaran kuesioner terhadap responden. Hasil penelitian ini dapat disimpulkan untuk hasil analisis koefisien determinasi adalah 0.644 . jadi sumbangan pengaruh dari variabel independent yaitu $64.4 \%$ sedangkan sisanya $35.6 \%$ dipengaruhi oleh faktor lain. Sedangkan kesimpulan untuk Uji $\mathrm{F}$ yaitu kualitas kegunaan (usability), kualitas informasi (information quality) dan kualitas interaski (interaction quality) secara bersama-sama berpengaruh terhadap kepuasan pengguna (user satisfaction). Kemudian untuk hasil Uji T yaitu dimensi information quality dan interaction quality berpengaruh positif dan signifikan terhadap user satisfaction. Untuk itu dibutuhkan rekomendasi untuk peningkatan kualitas website maxserver pada dimensi information quality dan interaction quality.
\end{abstract}

Kata Kunci: Webqual 4.0, Kualitas Website, Maxserver, PT. MCS.

\begin{abstract}
The services of a website needs to be measured to find out the level of user satisfaction and obtain feedback. In this research the quality of the Maxserver Website is measured using the Webqual 4.0 method. Webqual is an instrument that assesses the quality of a website according to the perception of end users. Multiple linear regression analysis is used to examine the relationship between dimensions of webqual 4.0 with user satisfaction. Respondents in this research are the users who have subscribed the product from Maxserver. The number of samples in this study were 122 respondents. The research data came from distribution of questionnaires to respondents. The conclusion of this research is coefficient of determination is 0.644 . So the contribution of the independent variable is $64.4 \%$ while the remaining $35.6 \%$ is influenced by other factors. While the conclusions of $F$ Test are usability, information quality and interaction quality which affected in user satisfaction. Then for the TTest results, the dimensions of information quality and interaction quality have a positive and significant effect in user satisfaction. For this reason, recommendations are needed to improve the quality of the maxserver website on information quality and interaction quality.
\end{abstract}

Keywords: Webqual 4.0, Website Quality, Maxserver, PT. MCS

http://ejournal.urindo.ac.id/index.php/TI 


\section{PENDAHULUAN .}

Saat ini perkembangan teknologi semakin pesat, hal ini kita bisa lihat dari banyaknya komunikasi antara individu, organisasi atau lembaga maupun kelompok tertentu untuk saling bertukar informasi. Pertukaran informasi ini dapat terjadi dengan adanya teknologi yang berhasil diciptakan oleh para peneliti-peneliti. Penelitian di bidang komunikasi dan teknologi informasi setiap harinya, selalu mengalami perkembangan yang cepat dan signifikan. Maka diperlukannya suatu aplikasi kepada pengguna untuk dapat melakukan pertukaran data atau informasi. Aplikasi tersebut berbasis online salah satunya website. Pada saat ini website telah banyak digunakan oleh perusahaan, organisasi, maupun individu sebagai media atau sarana dalam melakukan berbagai aktifitas pengolahan data untuk dapat menghasilkan informasi secara menyeluruh, yang nantinya dapat dilihat dan digunakan oleh semua pihak yang berkepentingan. Menurut (Meyliana, 2018) "Website memiliki peran dan fungsi yang sangat penting sehingga dalam perancangannya harus memperhatikan beberapa faktor yang dapat mempengaruhinya yaitu usability, user experience dan user interface".

PT. Maxindo Content Solution (MCS) berdiri sejak tahun 2008, adalah perusahaan nasional yang bergerak dalam bidang teknologi informasi yang menawarkan jasa IT konsultan, hosting, domain, secure socket layer (SSL), spam secure email, colocation server, dedicated server, cpanel license, dan manage service.

Sejauh ini, setelah layanan website maxserver pada PT. MCS diimplentasikan belum pernah di lakukan analisis kelayakan untuk meningkatkan kualitas informasi dan kualitas interaksi layanan tersebut baik dari usability, information quality, dan interaction quality. Kualitas website telah menjadi salah satu isu strategis dalam komunikasi dan transaksi dengan pelanggan.

Oleh karena itu diperlukan analisa tentang faktor apa saja yang mempengaruhi tingkat kualitas dari suatu website. Dari hasil analisa tersebut dapat dilakukan evaluasi untuk meningkatkan kualitas website. Menurut (Kharisma \& Anggraeni, 2018) “Persepsi pengguna tersebut terdiri dari dua bagian, yaitu persepsi tentang mutu layanan yang dirasakan (aktual) dengan tingkat harapan (ideal)". Sedangkan menurut (Hekhmatyar \& Supriyadi, 2017) “webqual merupakan salah satu metode atau teknik suatu pengukuran tingkat kualitas website berdasarkan persepsi pengguna akhir". Adapun Menurut (Fauziah \& Wulandari, 2018) "kualitas website diukur oleh pengguna dengan didasari oleh pengukuran kualitas website menggunakan webqual 4.0". Adapun instrument-instrumen penelitian yang digunakan dalam webqual 4.0 yaitu dimensi kemudahan penggunaan (Usability Quality), dimensi kualitas informasi (Information Quality), dan kualitas interaksi (Interaction Quality).

Berdasarkan analisis diatas peneliti termotivasi untuk melakukan penelitian dan menyusun suatu penelitian tentang pengaruh penggunaan website terahadap kepuasan pengunjung website. Untuk itu peneliti ingin memberikan solusi bagaimana mengetahui tingkat kualitas layanan pada website maxserver dengan melakukan pengukuran menggunakan metode webqual 4.0 .

\section{METODE.}

Metode penelitian yang di lakukan pada penelitian ini antara lain:

A. Dalam hal ini penulis melakukan observasi terhadap website www.maxserver.co.id untuk mengetahui website ini dan pengguna yang belum mengetahui website www.maxserver.co.id.

B. Angket atau kuesioner merupakan pengumpulan data yang dilakukan dengan memberikan sebuah kuesioner dengan berbagai pertanyaan langsung kepada responden. Pemilihan sample dan metode sampling yang benar merupakan faktor kunci yang berperan dalam pengumpulan data yang benar dan terukur dalam penelitian. Agar dapat menentukan jumlah sampel minimum, dapat dilakukan dengan perhitungan slovin dengan persamaan : 


$$
\begin{array}{ll}
n=\frac{N}{1+N d^{2}} & n=\frac{175}{1+175(0,05)^{2}} \\
\text { Keterangan: } & n=\frac{175}{1.4375} \\
n=\text { Ukuran sample } & n=121.739 \\
N=\text { Populasi } & \\
\mathrm{d}=\text { Tingkat ketepatan(presisi) } &
\end{array}
$$

Dalam penelitian ini tingkat ketepatan yang digunakan adalah $5 \%$ dari hasil yang didapat dilihat pada perhitungan di atas, didapat sampel minimum 6 . sebanyak 121,739 dibulatkan menjadi 122 responden. Sehingga penulis dapat menganalisa tentang kualitas layanan yang diberikan dari layanan website maxserver dengan target dari responden berkisar 122 responden.

\section{Wawancara}

Metode wawancara yaitu dengan melakukan tanya jawab dengan pihak admin IT, Customer Service, dan staff pegawai sebagai narasumber untuk mendapatkan semua data yang dibutuhkan, kemudian diolah menjadi sebuah informasi yang lebih akurat demi suksesnya penelitian ilmiah yang dibuat.

\section{Studi Kepustakaan}

Dalam penyusunan penelitian ini penulis mencari informasi melalui buku teks, ebook, jurnal, ejurnal dll tentang analisis kualitas sebuah website terhadap kepuasan pelanggan.

Menurut penelitian pada (Fathur \& Didik, 2017) "webqual merupakan salah satu metode atau teknik pengukuran kualitas website berdasarkan persepsi pengguna akhir". Webqual berdasar pada konsep Quality Function Deployment (QFD) yaitu proses yang berdasar pada "voice of customer" dalam pengembangan dan implementasi suatu produk atau jasa. Dari konsep QFD tersebut, webqual di susun berdasar pada persepsi pengguna akhir ( end user ) terhadap suatu website.

Webqual telah mengalami beberapa iterasi dalam penyusunan kategori dan butir-butir pertanyaannya. Versi terbaru adalah webqual 4.0 yang menggunakan tiga dimensi untuk mewakili kualitas dari website. Dimensi atau sub variabel dari webqual 4.0 disusun berdasarkan tiga area utama menurut(Ghafiki \&
Setyorini, 2015), adalah:

1. Usability

2. Mencakup "desain website" dan "kegunaan", misalnya tampilan web, kemudahan penggunaan, penganganan antar halaman dan gambar yang ditampilkan kepada pengguna.

3. Information Quality

4. Mengacu kepada kualitas dari konten website dan relevansi untuk keperluan pengguna misalnya, jumlah akurasi, konteks, format dan relevansi informasi.

Service Interaction Quality

Kualitas layanan interaksi yang di tawarkan oleh situs web untuk pengguna. Bagian ini dibagi menjadi "trust" dan "empati". Misalnya, masalah tentang transaksi, keamanan informasi, pengiriman produk, personalisasi dan komunikasi dengan pemilik situs web.

Analisis data dilakukan dengan menggunakan analisis regresi linier berganda. Sebelum itu perlu dilakukan uji validitas dan reliabilitas terlebih dahulu yang selanjutnya di lakukan uji asumsi klasik sebagai syarat terlaksananya analisis regresi linier berganda.

\section{HASIL DAN PEMBAHASAN}

Kuesioner online yang dibagikan sejak tanggal 15 november 2019 hingga 15 desember 2019 diisi oleh 122 responden. Responden penelitian Tugas Akhir ini didominasi oleh Pria. Jumlah responden berdasarkan jenis kelamin dapat dilihat pada Tabel 1

Tabel 1. Jenis Kelamin Responden

\begin{tabular}{|l|r|r|}
\hline \multicolumn{1}{|c|}{ Jenis Kelamin } & Jumlah & Persentase \% \\
\hline Pria & 87 & $71.3 \%$ \\
\hline Wanita & 35 & $28.7 \%$ \\
\hline Total & 122 & $100 \%$ \\
\hline
\end{tabular}

Sumber: ( Olahan penulis, 2019)

Mayoritas responden berusia antara 24 tahun hingga 37 tahun. Jumlah responden berdasarkan rentang usia dapat dilihat pada Tabel 2 
Tabel 2. Usia Responden

\begin{tabular}{|c|c|c|}
\hline Usia & Jumlah & Persentase $\%$ \\
\hline 17-23 Tahun & 10 & $8.2 \%$ \\
\hline 24-30 Tahun & 44 & $36.1 \%$ \\
\hline 31-37 Tahun & 56 & $45.9 \%$ \\
\hline >37 Tahun & 12 & $9.8 \%$ \\
\hline Total & 122 & $100 \%$ \\
\hline
\end{tabular}

Sumber: ( Olahan penulis, 2019 )

Responden berasal dari berbagai latar belakang profesi. Mayoritas responden merupakan karyawan swasta dan pegawai negeri. Jumlah responden berdasarkan profesi atau pekerjaan dapat dilihat pada Tabel 3

Tabel 3. Pekerjaan Responden

\begin{tabular}{|l|c|c|}
\hline \multicolumn{1}{|c|}{ Pekerjaan } & Jumlah & Persentase \% \\
\hline Mahasiswa & 15 & $12.30 \%$ \\
\hline Wirwaswasta & 23 & $18.90 \%$ \\
\hline Pegawai Negri & 32 & $26.20 \%$ \\
\hline Pegawai Swasta & 52 & $42.60 \%$ \\
\hline
\end{tabular}

Sumber: ( Olahan penulis, 2019 )

Berikut hasil ringkasan Tabel Regresi olahan dari SPSS.

Tabel 4. Ringkasan Tabel Regresi

\begin{tabular}{|c|c|c|c|}
\hline Variabel & $\begin{array}{c}\text { Koefisien } \\
\text { Regresi }\end{array}$ & $\mathrm{T}_{\text {hitung }}$ & Signifikansi \\
\hline Konstanta & 4.758 & 2.786 & 0.006 \\
\hline $\mathrm{X}_{1}$ & 0.106 & 1.624 & 0.107 \\
\hline $\mathrm{X}_{2}$ & 0.198 & 3.101 & 0.002 \\
\hline $\mathrm{X}_{3}$ & 0.466 & 4.829 & 0.000 \\
\hline Fhitung & 71.099 & & \\
$\mathrm{R}^{2}$ & 0.644 &
\end{tabular}

Sumber: (Olahan penulis, 2019)

Pengujian yang dilakukan pada analisis regresi linier berganda yaitu uji $\mathrm{F}$ dan uji $\mathrm{T}$. langkah analisis regresi dan prosedur pengujiannya sebagai berikut:

\section{a. Analisa Regresi Linier Berganda}

Persamaan regresi linier berganda tiga variabel independent adalah $b_{1}=0.106, b_{2}=0.198, b_{3}=0.466$. Nilai-nilai pada output kemudian

dimasukan ke dalam persamaan regresi linier berganda adalah:

$Y^{\prime}=a+b_{1} X_{1}+b_{2} X_{2}+b_{3} X_{3}$

$Y^{\prime}=4.758+0.106 X_{1}+0.198 X_{2}+0.466 X_{3}$

( $\mathrm{Y}^{\prime}$ adalah variabel dependent yang diramalkan, a adalah konstanta, $b_{1}, b_{2}$ dan $b_{3}$ ada koefisien regresi, dan $X_{1}, X_{2}, X_{3}$ adalah variabel independent).

Keterangan dari model regresi linier diatas adalah:

1. Nilai (Konstanta) menunjukan nilai sebesar 4.758 Artinya jika nilai variabel independent (bebas) adalah 0, maka variabel dependent (terikat) bernilai 4.758. Dalam penelitian ini, jika pengaruh Usability Quality, Information Quality, dan Interaction Quality bernilai 0 (nol), maka tingkat User Satisfaction bernilai 4.758

2. Nilai Koefisien Regresi Variabel Usability Quality $\left(b_{1}\right)=0.106$

Artinya jika nilai Usability Quality ditingkatkan 0.1 satuan, maka tingkat User Satisfaction akan meningkat sebesar 0.106 satuan dengan asumsi variabel independent lainnya tetap.

3. Nilai Koefisien Regresi Variabel Information Quality $\left(b_{2}\right)=0.198$

Artinya jika nilai Information Quality ditingkatkan 0.1 satuan, maka tingkat User Satisfaction akan meningkat sebesar 0.198 satuan dengan asumsi variabel independent lainnya tetap.

4. Nilai Koefisien Regresi Variabel Interaction Quality $\left(b_{3}\right)=0.466$

Artinya jika nilai Interaction Quality ditingkatkan 0.1 satuan, maka tingkat User Satisfaction akan meningkat sebesar 0.466 satuan dengan asumsi variabel independent lainnya tetap.

\section{b. Analisa Koefisien Determinasi}

Analisis R2 (R Square) atau koefisien determinasi digunakan untuk mengetahui seberapa besar prosentase sumbangan pengaruh variabel independent secara bersama-sama terhadap variabel dependent. Dari output tabel 4 model summary dapat diketahui nilai R2 (Adjusted R Square) adalah 0.644. Jadi sumbangan pengaruh dari variabel independent yaitu $64.4 \%$ sedangkan sisanya sebesar $35.6 \%$ dipengaruhi oleh faktor lain yang tidak di teliti. 


\section{c. Uji Koefisien Regresi Secara Bersama (Uji F)}

Uji $F$ digunakan untuk menguji pengaruh variabel independent secara bersama-sama terhadap variabel dependent.

Prosedur pengujiannya sebagai Berikut:

\section{Menentukan Hipotesa}

Ho : Variabel Usability Quality, Information Quality, dan Interaction Quality secara bersama-sama tidak berpengaruh terhadap User Satisfaction

$\mathrm{H}_{1}$ : Variabel Usability Quality, Information Quality, dan Interaction Quality secara bersama-sama berpengaruh terhadap User Satisfaction.

2. Menetukan Taraf signifikansi

Taraf signifikansi yang di gunakan 0.05

3. Menentukan F Fitung dan $\mathrm{F}_{\text {tabel }}$

Fhitung adalah 71,099 (pada tabel 4)

Ftabel dicari pada tabel statistik pada signifikansi $0.05 \mathrm{df}_{1}=$ $\mathrm{k}-1$ atau 3-1=2, dan $\mathrm{df}_{2}=\mathrm{n}-\mathrm{k}$ atau 122-3=119 ( $n=$ jumlah data; $k=j u m l a h$ variabel independent. Didapat $F_{\text {tabel }}$ adalah sebesar 3.072

4. Pengambilan Keputusan

- Jika $F_{\text {hitung }} \leq \mathrm{F}_{\text {tabel }}$ maka $\mathrm{H}_{0}$ diterima

- Jika F hitung $>F_{\text {tabel }}$ maka $\mathrm{H}_{0}$ ditolak

5. Kesimpulan

Dapat diketahui bahwa Fhitung (71.099) > F Fabel (3.072) maka $\mathrm{H}_{0}$ ditolak. Jadi kesimpulannya yaitu Usability Quality, Information Quality, dan Interaction Quality secara bersama-sama berpengaruh terhadap User Satisfaction.

\section{d. Uji Koefisien Regresi Secara Parsial (Uji T )}

Uji $T$ digunakan untuk menguji pengaruh variabel independent secara parsial terhadap variabel dependent. Prosedur pengujiannya sebagai berikut:

\section{Pengujian $\mathrm{B}_{1}$ (Usability Quality)}

- Menentukan Taraf Signifikansi, 0.05

- Menentukan thitung dan tabel. Thitung adalah 1.624 (pada Tabel 4 ). Ttabel dapat dicari pada tabel statistik pada signifikansi $0,05 / 2=0.025$ ( uji 2 sisi ) dengan $\mathrm{df}=\mathrm{n}-\mathrm{k}-1$ atau $122-3-1=118(\mathrm{k}$ adalah jumlah variabel independent ). Didapat $t_{\text {tabel }}$ sebesar 1.980

- Pengambilan Keputusan

- $t_{\text {hitung }} \leq \mathrm{t}_{\text {tabel }}$ atau $-\mathrm{t}_{\text {hitung }} \geq-\mathrm{t}_{\text {tabel }}$ jadi $\mathrm{H}_{0}$ diterima

- thitung $>$ ttabel atau - thitung $<-$ tabel jadi Ho ditolak

- Kesimpulan

Dapat diketahui bahwa thitung $(1.624)<t_{\text {tabel }}(1.980)$ jadi $\mathrm{H}_{0}$ di terima, kesimpulannya yaitu Usability Quality tidak berpengaruh terhadap User Satisfaction.

\section{Pengujian $\mathrm{B}_{2}$ ( Information Quality)}

- Menentukan Taraf Signifikansi, 0.05

- Menentukan thitung dan $t_{\text {tabel. }} T_{\text {hitung }}$ adalah 3.101 (pada Tabel 4 ). $T_{\text {tabel }}$ dapat dicari pada tabel statistik pada signifikansi 0,05/2 $=0.025$ ( uji 2 sisi ) dengan $\mathrm{df}=\mathrm{n}-\mathrm{k}-1$ atau $122-3-1=118(\mathrm{k}$ adalah jumlah variabel independent ). Didapat ttabel sebesar 1.980

- Pengambilan Keputusan

- thitung $\leq t_{\text {tabel }}$ atau $-t_{\text {hitung }} \geq-t_{\text {tabel }}$ jadi $H_{0}$ diterima

- $t_{\text {hitung }}>t_{\text {tabel }}$ atau $-t_{\text {hitung }}<-t_{\text {tabel }}$ jadi $H_{0}$ ditolak

- Kesimpulan

Dapat diketahui bahwa thitung (3.101) $>t_{\text {tabel }}$ (1.980) jadi $\mathrm{H}_{0}$ di tolak, kesimpulannya yaitu Information Quality berpengaruh terhadap User Satisfaction.

3. Pengujian $\mathrm{B}_{3}$ ( Interaction Quality)

- Menentukan Taraf Signifikansi, 0.05

- Menentukan thitung dan tabel. Thitung adalah 4.829 (pada Tabel 4 ). Ttabel dapat dicari pada tabel statistik pada signifikansi 0,05/2 $=0.025$ ( uji 2 sisi ) dengan $\mathrm{df}=\mathrm{n}-\mathrm{k}-1$ atau $122-3-1=118(\mathrm{k}$ adalah jumlah variabel independent ). Didapat tabel sebesar 1.980

- Pengambilan Keputusan

- thitung $\leq t_{\text {tabel }}$ atau $-t_{\text {hitung }} \geq-t_{\text {tabel }}$ jadi $H_{0}$ diterima

- thitung $>t_{\text {tabel }}$ atau $-t_{\text {hitung }}<-t_{\text {tabel }}$ jadi $H_{0}$ ditolak

- Kesimpulan

Dapat diketahui bahwa thitung (4.829) > tabel (1.980) jadi $\mathrm{H}_{0}$ di tolak, kesimpulannya yaitu Interaction Quality berpengaruh terhadap User Satisfaction.

\section{KEIMPULAN DAN SARAN}

\section{KESIMPULAN}

Berdasarkan hasil penelitian kualitas website terhadap Kepuasan Pengguna menghasilkan kesimpulan sebagai berikut:

1. Kualitas penggunaan tidak berpengaruh positif dan signifikan terhadap kepuasan pengguna website maxserver. Artinya setiap peningkatan kualitas penggunaan pada website, maka tidak akan berpengaruh terhadap Kepuasan Pengguna. 
2. Kualitas informasi berpengaruh positif dan signifikan terhadap kepuasan pengguna website maxserver. Artinya setiap peningkatan kualitas informasi pada website, maka akan meningkatkan Kepuasan Pengguna.

3. Kualitas interaksi berpengaruh positif dan signifikan terhadap kepuasan pengguna website maxserver. Artinya setiap peningkatan kualitas interaksi pada website, maka akan meningkatkan Kepuasan Pengguna.

Sehingga secara keseluruhan, penelitian ini memberi kesimpulan bahwa pengaruh Kualitas Penggunaan tidaklah menjadi pertimbangan yang utama dalam website maxserver PT. MCS dalam mempengaruhi Kepuasan Pengguna. Akan tetapi, pengaruh Kualitas Informasi dan Kualitas Interaksi yang lebih baik akan meningkatkan Kepuasan Pengguna terhadap website maxserver PT. MCS

\section{SARAN}

Berdasarkan penelitian yang telah dilakukan, maka selanjutnya penulis mengajukan beberapa saran yang dapat menjadi bahan pertimbangan dan masukan bagi pihak perusahaan yaitu sebagai berikut:

a. Sebaiknya pihak PT. MCS dapat memberikan perhatian lebih terhadap kualitas informasi, belum adanya informasi "Term of Service" dimana halaman informasi ini berisi dokumen legal (hukum) yang bisa dijadikan sebagai alat hukum jika terjadi masalah yang berhubungan dengan hukum, "Privacy Policy" dimana halaman ini berisi informasi bagaimana website mengelola informasi pengunjung. Dan "Disclaimer" berisi informasi penyangkalan atau pernyataan yang diberikan dengan tujuan agar pemilik atau pengelola website dapat memberikan informasi dan pengguna website dianggap secara otomatis mengikuti aturan-aturan yang dibuat oleh pemilik atau pengelola.

b. Membuat tampilan yang lebih menarik lagi agar para pengguna semakin tertarik untuk mengunjungi website maxserver.

\section{DAFTAR PUSTAKA}

[1]. Fauziah, D., \& Wulandari, D. (2018). PENGUKURAN KUALITAS LAYANAN BUKALAPAK.COM TERHADAP KEPUASAN KONSUMEN DENGAN METODE WEBQUAL 4.0. Jurnal Ilmu Pengetahuan Dan Teknologi Komputer, 3(2), 173-180. https://doi.org/https://doi.org/10.33480/jitk.v3i2.345

[2]. Ghafiki, R., \& Setyorini, R. (2015). PENGARUH KUALITAS WEBSITE TERHADAP KEPUTUSAN PEMBELIAN PADA SITUS BUKALAPAK.COM. Journal of Chemical Information and Modeling, 53(9), 1689-1699. https://doi.org/10.1017/CBO9781107415324.004

[3]. Hekhmatyar, O. G., \& Supriyadi, D. (2017). Measurement Satisfaction Information System Quality Service On BSI Using Webqual And CSI. Indonesian Jurnal on Computer and Information Technology, 2(2), 1-6. https://doi.org/https://doi.org/10.31294/ijcit.v2i2.27 72

[4]. Kharisma, M., \& Anggraeni, S. (2018). PENGARUH KUALITAS LAYANAN BJB NET TERHADAP KEPUASAN NASABAH BANK BJB RASUNA SAID MENGGUNAKAN METODE WEBQUAL 4.0. TECHNO Nusa Mandiri, 15(1), 13-18. https://doi.org/https://doi.org/10.33480/techno.v15i1 .52

[5]. Meyliana, A. (2018). Pengukuran Kualitas Situs Jual Beli Online Menggunakan Metode WebQual. Indonesian Journal on Software Engineering, 7(2), 14-20. https://doi.org/https://doi.org/10.31294/ijse.v4i1.623 2 